\title{
Aproximaciones a las poetas francesas de la $B e-$ lle Époque en España: traducciones actuales de la obra de Anna de Noailles
}

\author{
Irene ATALAYA FERNÁNDEZ \\ Universidad Autónoma de Madrid \\ irene.atalaya@uam.es \\ https://orcid.org/oOoO-0002-1281-4891
}

\begin{abstract}
Resumen
En los últimos años se ha producido un renovado interés por las poetas en lengua francesa de la Belle époque como muestra el flujo de sus traducciones en España. En este estudio nos centraremos en esbozar las traducciones de las poetas de la Belle Époque, cuáles fueron los principales canales de difusión de sus poemas, y haremos especial hincapié en las traducciones de Anna de Noailles, escritora muy conocida en su época y esporádicamente traducida por figuras célebres como Fortún, Marquina o Maristany. Actualmente, contamos con dos poemarios traducidos, Las pasiones y las tumbas, a cargo de Mireia Alonso Ribeiro (2011 [2020]), y El honor de sufrir, traducción de Julio Pollino Tamayo (2018). A través de un estudio diacrónico de las traducciones, veremos la recepción de su poesía gracias a un análisis traductológico de sus poemas.
\end{abstract}

Palabras clave: Traducción, recepción, literatura francesa, mujeres poetas, Anna de Noailles.

\section{Résumé}

$\mathrm{Au}$ cours des dernières années, on a constaté un regain d'intérêt pour les femmes-poètes de la Belle Époque, comme le montre le flux des traductions en Espagne. Dans cette étude, nous nous pencherons sur les traductions de ces poétesses et sur les principaux canaux de diffusion de leurs textes en mettant l'accent sur les traductions d'Anna de Noailles, autrice très renommée à son époque et traduite par des écrivains célèbres comme Fortún, Marquina ou Maristany. De nos jours, deux recueils ont été publiés: Las pasiones y las tumbas, traduit par Mireia Alonso Ribeiro (2011 [2020]), et El honor de sufrir, par Julio Pollino Tamayo (2018). À l'aide

${ }^{*}$ Artículo recibido el 16/06/2021, aceptado el 31/10/2021. 
d'un parcours diachronique des traductions de la comtesse, nous analyserons la réception de sa poésie grâce à une étude traductologique de plusieurs poèmes.

Mots clés: Traduction, réception, littérature française, femmes-poètes, Anna de Noailles.

\begin{abstract}
In recent years, there has been a renewed interest for French female poets as it has been proved by the translations workflow in Spain. The aim of this study is to define the Belle Époque translations as well as the main channels of reception emphasizing on Anna de Noailles' translations. Some of the work of this wellknown poet was translated by famous Spanish authors such as Fortún, Marquina or Maristany. Nowadays, two poetry books have been published: Las pasiones y las tumbas, translated by Mireia Alonso Ribeiro (2011 [2020]), and El honor de sufrir, by Julio Pollino Tamayo (2018). By means of a diachronic study of Noailles' translations, we will analyse the reception of her poetry throughout a study of some of her poems from a translation studies point of view.
\end{abstract}

Keywords: Translation, reception, French literature, women poets, Anna de Noailles.

\title{
1. Aproximación a las poetas de la Belle Époque a través de la traducción
}

En los últimos años se ha producido un renovado interés por las poetas en lengua francesa de la Belle Époque como muestra el flujo de traducciones en España con la llegada del siglo XXI. Si bien en vida de estas escritoras sus poemas en lengua castellana aparecen tímidamente en prensa o en alguna antología de la época, actualmente asistimos a una recuperación de sus obras, sin duda gracias al auge de los estudios de género y a la preocupación de los estudios literarios por rescatar del olvido los trabajos de numerosas mujeres.

El trato que reciben estas autoras es dispar dependiendo de la época. Durante las dos primeras décadas del siglo XX, los nombres de Anna de Noailles y de Lucie Delarue-Mardrus tuvieron su espacio en numerosas páginas de la prensa española. Es más, entre las mujeres antologadas por Díez Canedo y Fortún (1913) en su importante obra Poesía francesa moderna, encontramos tímidamente a estas dos poetas, destacadas por su poesía romántica, apasionada y tumultuosa, al igual que en Poesías excelsas (breves) de los grandes poetas (1914), en Florilegio. Las mejores poesías líricas griegas, latinas, italianas, portuguesas, francesas, inglesas y alemanas (1920) y en Antología general de poetas líricos franceses (1921), del visionario traductor y editor Fernando Maristany; y, finalmente, en El libro de los poetas. Antología universal del arte de la lectura de Juan Díaz Quevedo (s. a. 
¿1925?)1. No obstante, si el interés por Anna de Noailles se mantiene en el tiempo, aunque de forma intermitente, la recepción de Lucie Delarue-Mardrus decae por completo, pues no contamos con traducciones actuales de su obra.

La llegada de la primera década del siglo XX supone un punto de inflexión para la creación poética de mujeres en Francia (Corbí Sáez, 2014: 58). Nunca hasta entonces habían florecido al mismo tiempo tantas poetas, aunque permanecen en la historia literaria por sus escandalosas vidas o por desafiar las normas impuestas. La mujer-escritora era un ser híbrido, andrógino, una «juxtaposition de deux termes oxymoriques» (Collado, 2003: 48). Sin embargo, la categoría literaria que reside en el género, muchas veces enunciada por la crítica universitaria, no tiene ninguna base científica: no se puede negar que cada poeta presenta un estilo diferente y una forma de entender el mundo y la poesía. Muchas veces encasilladas en la poesía romántica y femenina, la tendencia de reagrupamiento de estas escritoras las excluye del propio campo literario (Fouchard, 2018: 35). Esta etiqueta, establecida por Charles Maurras (1905) en su crítica «Le Romantisme féminin», reagrupaba a varias poetas, entre ellas a Anna de Noailles, denigrando su poesía y considerándola inferior con respecto a la creación masculina:

Cette variété de féminisme est la plus brillante, mais la plus menaçante pour le genre humain tout entier. Sous prétexte d'accroître une juste et utile influence des femmes, ceci la diminue, et l'annule même (Maurras, 1905: 255).

La Belle Époque es un periodo bisagra entre dos siglos marcado por profundos cambios sociales y políticos antes de la Primera Guerra Mundial donde la modernidad llega para instalarse con la aparición de grandes progresos científicos y, en este clima desconcertante, nace una generación de mujeres dispuestas a hacer historia. La poesía es el género más cultivado por estas escritoras, pues tradicionalmente se ha asociado a la figura de la Musa: «La femme-poète est alors doublement mystifiée, surtout si ce qu'elle produit correspond à ce que le monde littéraire attend d'elle et donc si elle se conforme à l'image stéréotypée de la poétesse» (Izquierdo, 2009: 69). Aunque este género no sea económicamente el más rentable, hay una voluntad por parte de las escritoras de introducirse de lleno en el campo literario (Fouchard, 2018: 34).

En su obra pionera, Izquierdo (2009) analiza sesenta y cinco poemarios publicados entre 1900 y 1914 producidos por catorce mujeres escrito$\mathrm{ras}^{2}$. Actualmente en España, la más traducida, aunque en su época pasara

${ }^{1}$ Remito a los trabajos de Francisco Lafarga (2020a y 2020b), de donde se ha obtenido esta clasificación.

2 Natalie Barney, Marguerite Burnat-Provins, Gérard d'Houville (pseudónimo de Marie de Régnier), Marie Dauguet, Lucie Delarue-Mardrus, Jean Dominique (Marie Closset), Judith 
desapercibida, es Renée Vivien que cuenta con dos antologías poéticas: Nocturnos (2005) y Poemas (2007), ambas a cargo de Aurora Luque, poeta y traductora; Cenizas y polvo. Antología poética (2006), traducción de Joaquín Negrón3; Estudios y preludios: 1901 (2006), obra traducida por Jiménez Burillo4, además de varios poemas publicados en revistas literarias o académicas como Clarín ( $\left.{ }^{0} 42,2002\right)$, Renacimiento ( $\left.{ }^{0} 45 / 46,2004\right)$, Letra Clara (2004), El Robador de Europa (2005), El Maquinista de la Generación (2005) por Aurora Luque o en Lectora $\left(\mathrm{n}^{\mathrm{o}} 10,2004\right)$ por $\mathrm{M}^{\mathrm{a}}$ Dolores Martínez Muñoz. El interés por esta autora puede explicarse gracias a los numerosos estudios universitarios y tesis aparecidas a lo largo del siglo XXI en torno a su figura. Una de las traductoras más dedicadas a esta labor, Aurora Luque (2006: 22), reclama haber «traducido solamente a poetas que necesitaba [...]. Las he elegido con absoluta libertad, entendiendo acaso por libertad algo no muy distinto a la lealtad a un destino íntimo». Judith Gautier también cuenta con la primera traducción de su célebre El libro de Jade (2013) de la mano de Julián Gea5. En el caso de Anna de Noailles, aparece una selección realizada por Mireia Alonso Ribeiro en Las pasiones y las tumbas (2011 [ $2^{\mathrm{a}}$ edición 2020]), y El honor de sufrir (2018), traducción de Julio Pollino Tamayo 6 .

Por su continuidad en el panorama editorial español, además de por su éxito sin precedentes tanto en Francia como en España, nos centraremos en las traducciones de Anna de Noailles. Definida por sus contemporáneos de ambos lados de los Pirineos como romántica (véase Díez Canedo \& Fortún, 1913; Maurras, 1905), lo cierto es que la condesa es más que una poeta romántica, como demuestra Piquer Desvaux (1996), o postromántica (Allard, 2010: 132). En vida de Noailles, su presencia en España fue continua y variada (Lafarga, 2020a: 352) y su nombre aparecía asiduamente en la prensa. Generalmente, se trataban más cuestiones sociales que su labor literaria, debido al interés personal que la condesa suscitaba. Las traducciones, como muestra Lafarga (2020a), son parciales y escasas y hay que esperar a la llegada del siglo XXI para contar con poemarios o antologías completas. Izquierdo (2010: 128) asegura que la condesa de Noailles es un ejemplo ideal de musa romántica en perfecta alineación para ser reconocida en la esfera literaria como femme de lettres, pues su poesía satisfacía a la élite masculina de su tiempo con la que mantuvo excelentes relaciones literarias y personales, y, además, conjugaba una belleza exótica tan alabada por figuras como Colette en su dicurso de recepción en la Académie de Belgique

Gautier, Marie Krysinska, Amélie Murat, Anna de Noailles, Cécile Périn, Hélène Picard, Renée Vivien et Cécile Sauvage.

3 Título original en francés: Cendres et poussières. Recueil de poèmes.

4 Études et préludes.

${ }^{5}$ Le Livre de Jade.

${ }^{6}$ L'Honneur de souffrir. 
(1936). Probablemente, fue una de las poetas más apreciadas del elenco formado en su tiempo, que llega incluso a ocupar la pluma de Ortega y Gasset en su recién estrenada Revista de Occidente en 1923.

La traducción, con respecto a la propia creación literaria, ha sido históricamente considerada una labor inferior, al igual que comparada con la producción femenina, pero también ha sido una fuente inagotable de acceso al mundo literario para las mujeres traductoras (Castro, 2009; Fernández, 2012; Romero, 2015). Parece lógico que el creciente interés por la literatura escrita por mujeres se rescate gracias a la traducción, funcionando así como propuesta y protesta cultural. No obstante, desde el plano historiográfico, no se puede afirmar que haya existido una corriente feminista de recuperación de estas poetas de la Belle Époque en España. Se echa en falta una antología que reúna la obra de estas escritoras y que, además de traducir sus composiciones, contextualice y relacione la poesía de este periodo. No se trata, como apunta Castro (2009), de traducir mujeres por el simple hecho de que lo sean, sino porque sus obras tengan una importancia literaria ignorada por el canon patriarcal, como ocurre con las poetas de la Belle Épo$q u e$. Gracias a la traducción, se consigue modificar y ampliar el canon contemporáneo:

En lo que respecta a la recuperación de las escritoras clásicas mediante su reescritura a otras lenguas, la traducción puede servir como un instrumento para contextualizarlas, incorporando comentarios en los que las traductoras/es debatan sobre las razones que llevaron a esas obras a ser ignoradas (Castro, 2009: 72).

Se concibe así a mujeres y traducción como elementos periféricos respecto de un centro: la traducción es secundaria respecto a la escritura y el traductor respecto a la autoría, de igual modo que los feminismos son periféricos respecto al patriarcado y las mujeres respecto a los hombres (Castro, 2009: 67). Pero no hay que olvidar que para las poetas de la Belle Époque el mismo acto de escritura era ya un acto subversivo (Izquierdo, 2010) y que dicha contestación debe estudiarse y matizarse desde una perspectiva actual.

Ha habido en la actualidad un interés por parte de la cultura popular de recuperación de la condesa de Noailles (Boboc, 2010), tal y como evidencian los numerosos blogs en la red o las traducciones espontáneas que han surgido no solo en Francia, sino también en el mundo anglosajón o en España, como las realizadas por el traductor Miguel Ángel Frontán (2018) en el blog de Fausto Marcelo Ávila Ávila o el programa emitido en el ciclo de Mujeres malditas en Radio 5 «Anna de Noailles, libre y adelantada a su tiempo» (Alonso \& Corominas, 2014). Estas manifestaciones espontáneas alejadas de la crítica universitaria nos demuestran una tendencia popular por parte de los lectores actuales por dar a conocer el trabajo de escritoras menospreciadas por el canon masculino. 


\section{Las traducciones de Anna de Noailles desde una perspectiva actual}

De ascendencia real, la princesa Anna Élisabeth Bibesco Bassaraba de Brancovan (1876-1933) nace en París y se debate toda su vida entre su orgullo francés y la imagen oriental, herencia materna que sus contemporáneos prefieren procurarle, como la retratada por Zuloaga en 1913. En 1897 contrae nupcias con Mathieu de Noailles, convirtiéndose así en condesa de Noailles. Educada en la cultura y la música, su salón siempre estuvo frecuentado por los grandes nombres de la época: Proust, Barrès, Cocteau... Se define a sí misma como una ferviente republicana y reclama más poder para la mujer en la vida política. Abandera así, como primera presidenta, junto a algunas personalidades de la época, el premio conocido hoy en día como Fémina, alternativo al premio Goncourt, cuyo origen se debe sobre todo a las mujeres del comité Vie heureuse (Ducas, 2003), aunque nunca milita por la causa feminista. Es emblema de la Tercera República y prototipo de musa literaria. Conocida y alabada por su poesía, pero criticada por su prosa, publica numerosos poemarios y tres novelas, además de sus memorias en Le Livre de ma vie. Es evidente que la poesía, por sus características intrínsecas, es un género permitido a las mujeres de su tiempo. Su primer poemario, Le Cour innombrable (1901), obtiene un éxito sin precedentes para una mujer. Como muchos de sus contemporáneos, publica ya algunos de estos poemas en las prestigiosas Revue de Paris y Revue des Deux Mondes: «Ce premier recueil célèbre la vie et ses beautés à travers l'amour de la nature, à la fois perçue comme la matrice et le viatique de l'homme» (Allard, 2010: 17).

\subsection{Las pasiones y las tumbas (2011, 2020)}

En España, debemos esperar a 2011 para contar con el primer volumen de poesía traducido por Mireia Alonso Ribeiro, Las pasiones y las tumbas, aunque ya en 2007 había publicado en la revista literaria Fábula cuatro poemas extraídos del poemario Les Vivants et les morts (1913) y dos de ellos se reproducen exactamente en la mencionada antología.

Las pasiones y las tumbas corre a cargo de la editorial Torremozas, especializada en literatura escrita por mujeres, que presta particular atención a la poesía, al relato corto y al ensayo, géneros «menores» con respecto a la novela. Fundada por la poeta Luzmaría Jiménez Faro en 1982, la casa cuenta con más de ochocientos títulos nacionales e internacionales (véase Porpetta, 2016). Además, un dato muy interesante es que las versiones poéticas van siempre acompañadas de su texto original y la mayoría de sus traducciones van firmadas por mujeres, aunque no exclusivamente. Se trata de una editorial cuya valiosa aportación a la poesía escrita por mujeres merece ser resaltada en el polisistema literario español. 
Las pasiones y las tumbas se abre con un paratexto sobre la poesía de Noailles, centrándose en caracterizar su estilo7. Tal y como apunta Enríquez Aranda (2003: 334-335), los prólogos redactados por los traductores proporcionan información en relación con tres temas principalmente. En primer lugar, facilitan datos sobre el autor; seguidamente, explican en qué entorno cultural aparecieron las obras originales; y, por último, y el más interesante, son una mina del pensamiento traductológico del autor-traductor. No siempre es evidente este último punto, pues muchas veces este no desarrolla su metodología, ni la relación de su traducción con el polisistema cultural y literario de llegada. No parece baladí señalar que el prólogo es el único espacio en el que el traductor puede justificarse o explicar su proceder. Poco nos revela, sin embargo, la traductora sobre las dificultades o sobre su concepto de la traducción poética, si bien nos deja suponer cierta insatisfacción inherente a todo traductor poético: la poesía de la condesa «está impregnada de una gran musicalidad y colorismo, posee una sonoridad imposible de restituir completamente en la traducción, con algo de intuitivo y de poco trabajado, como si se dejara llevar por el sentimiento en un arrebato de placer» (Alonso Ribeiro, 2011: 12).

Al tratarse de una edición bilingüe, se cumple así el instrumento de contextualización, como señalaba Castro (2009), y, además de esbozar algunos datos sobre la vida de la autora, el lector se sumerge en el yo poético de la condesa. Por otro lado, el título de esta antología, muy acertado, responde a las dos grandes temáticas que atormentaron a su autora: el amor y la muerte. El título de la antología viene inspirado de su poemario Les Vivants et les morts que se divide en cuatro etapas en las cuales encontramos «Les passions» y «Les tombeaux»; es, además, un buen reclamo editorial pues la antítesis de ambos términos resulta muy sugerente para el lector.

La antología se presenta como un medio excelente para dar a conocer una selección de poesías. Hay un proceso consciente de selección por parte de la antóloga-traductora, aunque este sea muchas veces de carácter subjetivo, ya que la elección resulta fruto de una afinidad estética. Existen dos ediciones de esta obra, la última recientemente aparecida en agosto de 2020. Al contrario de la primera edición, que incluye los poemas originales al final del volumen, esta segunda edición, mucho más cuidada, nos presenta el texto original junto con la traducción y se menciona el poemario de donde ha sido extraído, dato que no aparecía en la anterior, de menor rigor literario. Igualmente, se han ordenado los textos por orden cronológico y se

\footnotetext{
7 Entendemos el paratexto en traducción como «both the peritextual and epitextual kind [which] offer a great deal of information when they accompany translations, including clues regarding the visibility of the translator, the target readership, the aim of the translation or the concept of translation favoured by the specific culture and/or publisher, as reflected in the way the text is presented in the title page» (Tahir-Gürçağlar, 2011: 113-116).
} 
han incluido cinco nuevos poemas en el apartado de «Las pasiones» ${ }^{8} \mathrm{y}$ ocho más en la sección de «Las tumbas»9. Esta segunda edición, aparte de ser visualmente más vistosa, es más completa e interesante para sus lectores.

Con motivo de la primera edición de la obra, el crítico literario Jaime Siles (2012: 14) alaba la cuidada selección realizada por la traductora que «permite ver la unidad y riqueza de su mundo [el de Noailles], el colorismo y la musicalidad de su escritura» y añade la importancia que tiene una poeta como ella para la literatura actual española, además de señalar la atemporalidad de la poesía:

La condesa de Noailles representa una época en la que la palabra poética no era la de hoy, pero es muy posible que poetas de hoy encuentren algo de hoy en ella, porque la poesía verdadera -y la suya lo es- no acaba nunca de pasar: es ajena a las modas y está siempre a la espera de un lector que sepa interpretarla (Siles, 2012: 15).

Hay que matizar quizá algún desliz en la traducción, pues vemos una evolución en el título del primer poemario de la condesa, Le Coeur innombrable, que va desde El corazón innombrable (Alonso Ribeiro, 2003) a $E l$ corazón innumerable (Alonso Ribeiro, 2011: 11; 2020: 9) en ambos prólogos de las dos ediciones de Torremozas hasta El corazón sin número (Noailles, 2020: 25) en la localización de los originales en segunda edición. Siles también habla de «El corazón innumerable» en su reseña periodística, pero en ningún caso podríamos hablar de «innombrable», pues estaríamos ante una falsa equivalencia.

Por otro lado, es interesante señalar el trabajo de reescritura por parte de la traductora entre ambas ediciones. No resulta sistemático para todas las composiciones, pero la labor de la traductora de poesía parece no tener fin y cada vez que se enfrenta a nueva lectura del poema original se desvela ante sus ojos una nueva traducción. Muchas veces los cambios son sutiles y solo afectan al ritmo de los versos como en «Nous avons attendu...» de Les Forces éternelles (1920):

- Mais cessant de nous taire et cherchant à comprendre

L'ineffable plaisir d'un sort brulant et tendre,

Nous fûmes submergés d'un étrange malheur.

8 «La primera pena» («Le premier chagrin») de L'Ombre des jours (1902); «Tanto soñé contigo...» («J'ai tant rêvé pour vous...»), «Andaba junto a ti... » («Je marchais près de vous»), «Ternura» («Tendresse»), de Les vivants et le morts (1913); «No permite el amor... » («L'amour ne laisse pas...») de Les Forces éternelles (1920).

9 «Versos, pese a la sangre...» («Mes vers, malgré le sang...») de Les Éblouissements (1907); «Dios mío, sé que hay...» («Mon Dieu, je sais qu’il faut...), «Así los días ligeros...» («Ainsi les jours légers...», «Parece que la muerte...» («Il paraît que la mort...»), de Les Vivants et le morts (1913); «Realmente hiciste bien...» («Certes, vous fites bien...»); «Hastío» («Lassitude») de Les Forces éternelles (1920); «LXXX» de L'Honneur de souffrir (1927); «No hay nada que no amara...» («Il n'est rien qui n'ait plu...) de Derniers vers et poèmes d'enfance (1933). 
Pourtant, parfois la joie et la source du rire

Comme au flanc d'un coteau court autour de mon cœur [...]

(Noailles, 2020: 66)

Trad. de Mireia Alonso (Noailles 2011: 37)

- Pero luego, rompiendo el silencio, queriendo

comprender el placer inefable de esa suerte tierna y ardiente, nos invadió un dolor

extraño. Sin embargo, a veces, la alegría, la fuente de la risa, me corre alrededor del corazón igual que por una colina [...]
Trad. de Mireia Alonso (Noailles 2020: 67)

Mas, rompiendo el silencio al querer comprender

el placer inefable de nuestra suerte ardiente

nos inundó una extraña desdicha. Sin embargo,

a veces, la alegría, la fuente de la risa

corre en mi corazón como en una colina

$[\ldots]$

La traductora decide en la segunda versión respetar el número de versos del original dándole elasticidad y eliminando adjetivos como «tierno»e incluso consiguiendo una rima asonante al final de la estrofa («risa» $\mathrm{y}$ «colina»). Vemos el mismo procedimiento en los últimos versos de la composición XXIV de Poème de l'amour (1924): «Je croirais dormir du sommeil suprême/dans ton bras, fermé sur mon être étroit...» (Noailles, 2020: 70), que pasa de ser «Creería que duermo su sueño supremo/mi estrecho ser en tu abrazo encerrado...» (Noailles, 2011: 39); a "Creería que duermo el sueño supremo/tu abrazo cerrado en mi estrecho ser...» (Noailles, 2020: 71).

\subsection{El honor de sufrir (2018)}

En 2018, aparece en formato libre en la red la única traducción completa del poemario L'Honneur de souffrir (1927) a cargo de Julio Pollino Tamayo. Este incansable traductor, de forma amateur, cuenta con un gran repertorio de traducciones disponibles gratuitamente en internet que pueden consultarse mayoritariamente en la página SlideShare. Volvemos a encontrar la necesidad por parte del gran público de conocer y de dar a conocer la poesía de Noailles de forma altruista. Así lo expresa el propio traductor:

Traduzco por puro placer, diversión, y sobre todo para difundir gratuitamente aquellas cosas inéditas o mal traducidas al español que subjetivamente considero valiosas, y que no han tenido la suerte de encontrar su público, o el reconocimiento que creo que merecen. En cuanto a Anna de Noailles, la descubrí por azar investigando sobre Marie Lenéru, creo que la mencionaba en sus diarios, o que había escrito el prólogo de alguno de sus libros, no recuerdo. En cuanto leí el título de El honor de sufrir surgió el flechazo, leí fascinado el primer 
poema y me puse a traducir el libro completo de inmediato ${ }^{10}$.

L'Honneur de souffrir, una de las últimas obras de Anna de Noailles, nace en un momento de crítica por parte de los surrealistas de su poesía. La condesa ha perdido recientemente a varios seres queridos, Barrès, Proust, Charles Demange, y así se respira desde la primera página: la obra está dedicada "À mes amis qui m'ont quittée, que je ne quitte point» (Noailles, 1927), y se abre con un epígrafe de la más mortal de las divinidades, Antígona, «J'aurai plus longtemps à plaire à ceux qui sont sous terre qu'à ceux qui sont ici». El tono dramático de la obra está asegurado, al igual que el carácter antirreligioso de su poesía. Noailles rechaza por completo la inmortalidad (Perry, 1997) y se aferra a la muerte. Antepenúltimo poemario de la condesa, esta obra gira en torno a la temática de la muerte indisociable del amor (Allard, 2010: 85). Estamos ante una poesía mucho más corta y más directa, sin grandes florituras. La muerte le obsesiona y esto se traduce en una escritura sobria de arte menor. Por ello, abandona el uso del alejandrino y se acerca a los versos impares. Se refugia en la muerte para no tener que enfrentarse a su propia vejez. Parece que el sufrimiento es la única respuesta posible para sobrellevar su propia existencia (Izquierdo, 2007: 6364).

Vamos a analizar uno de los poemas de esta obra a través de las dos versiones diferentes en castellano con las que contamos en la actualidad. Como matiza Connolly (2001: 172), el enfoque más útil para cotejar traducciones de un mismo poema sin hacer juicios de valor es examinar las diferentes estrategias empleadas por los traductores. Aunque existen numerosas teorías sobre la traducción poética y su posibilidad o imposibilidad, la relación entre teoría y práctica ha sido siempre problemática (Connolly, 2001: 172):

XLV L'Honneur de souffrir

J'aurais pu ne jamais connaître

Le dur besoin de ne plus être.

Mais puisque à jamais tu te tais, Puisque se sont défaits tes yeux, Je songe d'un cœur radieux Au néant qui m'épouvantait. - Car ma peur de mourir, c'était L'angoisse de te dire adieu...

(Noailles, 1927: 78)

\begin{tabular}{|c|c|}
\hline $\begin{array}{r}\text { XLV El } \\
\text { ad. de Mireia }\end{array}$ & XLV El honor de sufrir \\
\hline
\end{tabular}

${ }^{10}$ Comunicación personal de Julio Pollino Tamayo a Irene Atalaya (15 de octubre de 2020). 
Habría podido no conocer nunca La dura exigencia de ya no ser.

Mas puesto que te callas para siempre, Puesto que tienes los ojos deshechos, Contemplo con un corazón radiante

Esa nada que me aterrorizaba.

-iPuesto que todo mi miedo a morir

Era la angustia de decirte adiós!
Podría no haber conocido jamás La dura necesidad de no estar ya Pero puesto que para siempre callas Puesto que se han caído tus ojos Pienso con el corazón radiante En la nada que me espantaba Porque mi miedo a morir, era La angustia de decirte adiós...

Hay que distinguir entre la traducción poética y la traducción de poesía, siendo la primera un acto de creación. El poema original de ocho versos tiene una rima consonante aabccbbc. Las dos traducciones españolas sacrifican la rima, aunque mantienen el número de versos del poema original, así como la estructura. La polémica sobre si mantener o no la rima, como era el caso cuando Maristany tradujo la poesía de la condesa, ha pasado a un segundo plano y la traducción se debate hoy en día entre la exactitud y la búsqueda del efecto estético (Ellrodt, 2006). El lector o receptor de la poesía debe aceptar el reto al que el traductor se enfrenta y la distancia que separa el original de la traducción. En general, la traducción de Pollino se mantiene más cerca del texto original y Alonso Ribeiro se permite más licencias poéticas cercanas a la recreación. No existe una sola interpretación del texto poético, por lo que pueden existir tantas traducciones como interpretaciones haya del mismo poema.

Otro ejemplo se puede ver en la siguiente composición del mismo poemario:

\section{L'Honneur de souffrir \\ Jadis je m'aimais, \\ Tu sais quel orgueil \\ Parfois animait \\ Ma voix et mon œil. \\ - L'esprit sombre et froid, Je hais moi sans toi. \\ (Noailles, 1927: 127)}

LXXX El honor de sufrir

Trad. de Mireia Alonso (Noailles, 2020:

131)

Antes me quería,

Ya sabes qué orgullo

me animaba a veces

la voz y los ojos.

- Alma oscura y fría,

Me odio yo sin ti.
LXXX El honor de sufrir Trad. de Julio Pollino (Noailles, 2018: 89)

Antaño me amaba

Sabes qué orgullo

A veces animaba

Mi voz y mi mirada

El espíritu sombrío y frío

Me odio sin ti. 
En ambas traducciones volvemos a perder la rima cruzada (ababcc) del sexteto, pero se mantienen los hipérbatos y los asíndeton de esta composición casi encriptada. Ambas traducciones dejan a la interpretación de quien lee el primer verso «me quería» o «me amaba», mientras que la versión francesa deja claro quién es el sujeto y cómo el paso del tiempo ha ido mermando el amor propio de la poeta al haber sido despojada de aquel amor desconocido: «Je hais moi sans toi» (v. 6).

\section{Conclusiones}

Las escasas traducciones que existen actualmente de la obra de Noailles nos ofrecen, sin embargo, un panorama de la evolución espiritual de la poesía de la condesa. Por un lado, la selección de Alonso Ribeiro ofrece al lector una muestra desde las primeras composiciones basadas en la naturaleza y el romanticismo que emanan de la obra de Hugo o Musset al naturisme de Francis Jammes o de Gide. Por otro lado, gracias a la labor de Pollino Tamayo, se aprecia una poesía que bascula entre la sinceridad del modernismo o el deseo y exaltación del cuerpo y la voluptuosidad, y entre la desesperación y la angustia escatológica que aparece en el L'Honneur de souffrir y que nos transporta hacia el más allá (Allard, 2010: 19). Es evidente que la traducción poética se genera desde la periferia y más si se trata de figuras arrinconadas por la historia de la poesía. Por tanto, la labor desinteresada de traductores como Pollino o el empeño procurado por editoriales como Torremozas permiten ensanchar nuestras miras poéticas. Es importante la contextualización que realiza Mireia Alonso para poder resaltar el valor de la obra de Noailles, vanguardista para su tiempo por las razones señaladas a lo largo de este estudio. Desde una perspectiva actual, su poesía puede resultar arcaica o démodée, pero el verso libre utilizado por ambos traductores aporta cierta modernidad a su obra. Igualmente, la elección del poemario por parte de Pollino Tamayo se acerca más a una poesía actual, corta y directa, que puede interesar al gran público no solo por sus características históricas sino por la fuerza de la temática siempre universal de esos versos.

Poesía casta en apariencia, tenía su razón de ser y, aunque como apunta Allard (2010: 125), Anna de Noailles nunca militó en la causa feminista, su rol literario como mujer incomodó a sus contemporáneos. Esta prolífica poeta nos demuestra una evolución de la poesía antes de las vanguardias que denota un corazón atormentado por la muerte y la enfermedad. Es evidente que el olvido se acentúa cuando el que escribe es poeta, pero, como tan acertadamente apunta Bellessi (1997),

[...] la creación de una genealogía de escritoras, su descubrimiento y lectura, es una vía fundamental para la constitución de aquel yo productor, tanto de lectora como de autora, así como su inserción posterior a una herencia más vasta que también, indudablemente, nos 
pertenece y constituye. [...] Alteridad en algún espacio de mismidad: algo que los traductores varones ejercitaron durante siglos, con textos donde sus autores exploraban múltiples vínculos con el mundo, entre ellos la hermandad masculina, o la relación con mujeres en diversas funciones, o el paradigma de lo «femenino», es decir, la mujer escrita. La escritura, la reflexión crítica y la traducción, produciendo [...] cambios milimétricos pero profundamente desestabilizadores de cánones discursivos previos y de las propias lenguas que los susten$\tan$.

Falta aún mucho por hacer en los campos de la historia literaria y de la historia de traducción, pero, paulatinamente, asistimos a una recuperación europea de la «historia de textos de mujer» y no tanto de una «historia literaria de mujeres» desde una perspectiva cultural común entre países y lenguas (Planté, 2003: 667).

\section{REFERENCIAS BIBLIOGRÁFICAS}

Allard, Marie-Lise (2010): Anna de Noailles: entre prose et poésie. Thèse doctorale sous la direction de Bruno Curatolo. Besançon, Université de FrancheComté.

ALONSO RIBEIRO, Mireia (2007): «Un corazón innombrable: Anna de Noailles». Fábula, 23, 74-84.

Alonso RibeIRO, Mireia (2011): «Un halo de muerte», in A. de Noailles, Las pasiones y las tumbas. (Edición bilingüe). Prólogo y traducción de Mireia Alonso Ribeiro. Madrid, Torremozas, $1^{\text {a }}$ edición, 9-18.

Alonso Ribeiro, Mireia (2020): «Un halo de muerte», in A. de Noailles, Las pasiones y las tumbas. Traducción e introducción de Mireia Alonso Ribeiro. Madrid, Torremozas, $2^{\text {a }}$ edición aumentada, 7-17.

Alonso, Valle \& Jordi CoRominas (2014): «Mujeres malditas: Anna de Noailles, libre $\mathrm{y}$ adelantada a su tiempo». Radio $5 . \quad$ URL: https://www.rtve.es/alacarta/audios/mujeres-malditas/mujeresmalditas-anna-noailles-libre-adelantada-su-tiempo-24-06-14/2629028/

BELLESSI, Diana (1997): "Género y traducción», in L. Bradford (ed.), Traducción como cultura. Rosario, Beatriz Viterbo, 93-97. URL: http://www.cervantesvirtual.com/obra/genero-y-traduccion/

Bовоc, Alina (2010): «L'image d'Anna de Noailles dans la presse alternative». Comunicare Interculturală și Literatură, 4: II, 355-358. URL: https://www.ceeol.com/search/article-detail?id=590052

CASTRO VÁzQUEZ, Olga (2009): «(Re)examinando horizontes en los estudios feministas de traducción: ¿hacia una tercera ola?». MonTi, 1, 59-86. DOI: https://doi.org/10.6035/MonTI.2009.1.3 
COLETTE (1936): Discours de réception à l'Académie royale belge de langue et littérature françaises. París, Grasset.

Collado, Mélanie E. (2003): Colette, Lucie Delarue-Mardrus, Marcelle Tinayre. Émancipation et résignation. París, L'Harmattan.

ConNolly, David (2001): «Poetry Translation», in M. Baker (ed.), Routledge Encyclopedia of Translation Studies. Londres/Nueva York, Routledge, 170176.

CORBí SÁEZ, María Isabel (2014): «La poesía francesa escrita por mujeres: reflexiones en torno a un estado de la cuestión y propuestas para su investigación en los albores del tercer milenio». Cuadernos de Filología Francesa, 25, 53-65. URL: http://hdl.handle.net/10045/50927

DÍEZ-CANEDO, Enrique \& Fernando FORTÚN (1913): La poesía francesa moderna. Madrid, Renacimiento. URL: https://sirio.ua.es/libros/BFilosofia/canedo/index.htm

DUCAS, Sylvie (2003): «Le prix Femina: la consécration littéraire au féminin». $R e-$ cherches Féministes, 16: 1, 43-95. DOI: https://doi.org/10.7202/007343ar

ELLRODT, Robert (2006): «Comment traduire la poésie ?». Palimpsestes, hors serie. DOI: $10.4000 /$ palimpsestes.247

ENRÍQUEZ ARANDA, María Mercedes (2003): «Descripción y naturaleza del prólogo en la traducción literaria: un estudio práctico». Interlingüística, 14, 331340 .

FERNÁNDEZ, Fruela (2017): «De la profesionalización a la invisibilidad: las mujeres en el sector de la traducción editorial». TRANS, 16, 49-64. DOI: https://doi.org/10.24310/TRANS.2012.voi16.3211

FOUCHARD, Flavie (2018): «Les femmes-poètes de la Belle Époque et l'histoire littéraire du XX $\mathrm{XX}^{\mathrm{e}}$ siècle», in $\mathrm{M}^{\mathrm{a}}$ Vicenta Hernández Álvarez (coord.), Escritoras en lengua francesa. Renovación del canon literario. Granada, Comares, 31-40.

FrontÁN, Miguel Ángel (2018): «Poemas de Anna de Noailles», in Blog de Fausto Marcelo Ávila Ávila. URL: http://faustomarcelo.blogspot.com/2018/03/poemas-de-anna-de-noailles.html

IZQUIERDO, Patricia (2007): «Lucie Delarue-Mardrus et Anne de Noailles ou l'impossible écriture du vieillissement», in A. Keilhauer (ed.), Vieillir féminin et écriture autobiographique. Clermont-Ferrand, Presses universitaires Blaise Pascal, 57-70.

IZQUIERDO, Patricia (2009): Devenir poétesse à la Belle Époque (1900-1914). Étude littéraire, historique et sociologique. París, L'Harmattan (coll. «Espaces littéraires»).

IZQUIERDO, Patricia (2010): «Entre traduction et subversion. Stratégies d'écriture des femmes poètes à la Belle Époque (1900-1914)», in P. Godi-Tkatchouk (ed.), Voi(es)x de l'autre. Poètes femmes XIXe-XXIe siècle. Clermont-Ferrand, Presses universitaires Blaise Pascal, 125-138. 
LAFARGA, Francisco (2020a): «Traducciones españolas de la obra de Anna de Noailles». Transfer, 15, 351-370. URL: https://revistes.ub.edu/index.php/transfer/article/view/30207

LAFARGA, Francisco (2020b): «La poesía francesa en las antologías de Fernando Maristany». La Main de Thôt, 7. URL: http://revues.univ-tlse2.fr/lamaindethot/index.php?id=748.

LuQUe, Aurora (2006): Poética y poesía. Aurora Luque. Madrid, Fundación Juan March. URL: https://www.march.es/ciclos/2145/

MAURRAS, Charles (1905): «Le Romantisme féminin», in Ch. Maurras, L'avenir de l'intelligence. París, Albert Fontemoing, 155-255.

NOAILlES, Anna de (1927): L'Honneur de souffrir. París, Bernard Grasset.

NOAILLES, Anna de (2011 [2020]): Las pasiones y las tumbas. (Edición bilingüe). Prólogo y traducción de Mireia Alonso Ribeiro. Madrid, Torremozas.

NOAILLES, Anna de (2018): El honor de sufrir. Traducción de Julio Pollino Tamayo. Sitio web SlideShare. URL: https://es.slideshare.net/JulioPollinoTamayo/el-honor-de-sufrir-19231927-anna-de-noailles-poemario.

PERRY, Catherine (1997): «Retour au mythe païen dans l'œuvre d'Anna de Noailles». Religiologiques, 15 (printemps). URL: https://www.religiologiques.uqam.ca/no15/perry.html

PIQUER DESVAUX, Alicia (1996): «Narcisismo, alteridad y vitalismo en la poesía de Anna de Noailles», in M. Segarra \& À. Carabí (eds.), Amor e identidad. Barcelona, PPU, 77-86. URL: http://diposit.ub.edu/dspace/handle/2445/34250

PlanTÉ, Christine (2003): «La place des femmes dans l'histoire littéraire: annexe, ou point de départ d'une relecture critique ?». Revue d'Histoire Littéraire de la France, 103: 3, 655-668. DOI: https://doi.org/10.3917/rhlf.033.0655

PORPETTA, Marta (2016): «Entrevista a Marta Porpetta (Ediciones Torremozas)». Biblioteca Virtual Miguel de Cervantes. URL: http://www.cervantesvirtual.com/nd/ark:/59851/bmcmg9m7

ROMERO, Dolores (2015): «Mujeres traductoras en la Edad de Plata (1868-1939): identidad moderna y affidamento». Hermeneus, 17, 179-207. URL: https://recyt.fecyt.es/index.php/HS/article/view/44971

SILES, Jaime (2012): «El corazón innumerable». ABC Cultural, 28.01.2012, 14-15.

TAHIR-GÜRÇAĞLAR, Şehnaz (2011): «Paratexts», in Y. Gambier \& L. van Doorslaer (eds.), Handbook of Translation Studies. Ámsterdam, John Benjamins, vol. 2, 113-116. 